\title{
Arte, Educação Matemática E Empatia: Algumas Reflexões
}

\author{
Art, Mathematics Education And Empathy: Some Reflections
}

\author{
Antonio Carlos Brolezzi* \\ Instituto de Matemática e Estatística (IME-USP) \\ Iuri Naoto Nobre Ota** \\ Escola Municipal de Educação Básica Adamastor Baptista (EMEB Adamastor Baptista)
}

\begin{abstract}
Resumo
A associação entre Arte e Matemática pode ser estabelecida considerando a Matemática existente em produções artísticas como arquitetura, escultura, música e pintura, isto é, em obras prontas e acabadas. É nesse sentido que a corrente filosófica do Logicismo entendia a relação entre beleza e Matemática. Mas a arte da Matemática está também em sua construção, como afirmava a corrente do Intuicionismo. Nesse artigo trazemos reflexões, com base em revisão bibliográfica, sobre o papel da apreciação estética, da criatividade, empatia e imaginação na criação da Matemática, tanto no seu aspecto de área de pesquisa científica como na Educação Matemática. Apresentamos algumas reflexões com base no conceito de empatia, originado da experiência estética.
\end{abstract}

Palavras-chave: Arte; Educação Matemática; Criatividade; Empatia; Imaginação

\begin{abstract}
The association between Art and Mathematics can be established considering the mathematics existing in artistic productions like architecture, sculpture, music and painting, that is, in finished works. It is in this sense that the philosophical current of Logicism understood the relation between beauty and mathematics. But the art of mathematics is also in its construction, as the current of intuitionism asserted. In this article we present reflections, based on a bibliographical review, on the role of aesthetic appreciation, creativity, empathy and imagination in the creation of Mathematics, both in its aspect of scientific research and in Mathematics Education. We present some reflections based on the concept of empathy, originated from aesthetic experience.
\end{abstract}

Keywords/Palabras clave: Art; Mathematics Education; Creativity; Empathy; Imagination

\section{Introdução}

Arte e Matemática são áreas bastante distintas da cultura humana. Na escola, as duas disciplinas possuem modos de proceder muito diferentes quanto aos objetivos, práticas de sala

\footnotetext{
* Livre-docente pela Faculdade de Educação da Universidade de São Paulo (FEUSP). Professor Associado do Instituto de Matemática e Estatística da Universidade de São Paulo (IME-USP), São Paulo, São Paulo, Brasil. Email: brolezzi@ime.usp.br.

${ }^{* *}$ Licenciado em Matemática pelo Instituto de Matemática e Estatística da Universidade de São Paulo (IMEUSP). Aluno do Mestrado Profissional em Ensino de Matemática do IME-USP. Professor de Matemática da EMEB Adamastor Baptista, Franco da Rocha, SP, Brasil. E-mail: iuriota@gmail.com.
} 
de aula e avaliação. Mas parece interessante investigar a relação entre esses dois campos visando refletir sobre o ensino de Matemática, uma vez que tanto na pesquisa quanto no ensino de Matemática, tem-se procurado estabelecer relações entre essas duas formas de atividade cultural (CELLUCCI, 2015).

A relação entre Arte e Matemática, como a explorada por Le Lionnais (2004), pode ser estabelecida a partir da consideração de que existe muita Matemática em obras de arte de pintores, escultores ou arquitetos. Em educação Matemática, a chamada "grande arte" também é objeto de consideração em pesquisas que investigam a relação entre a contemplação de obras de arte prontas (pinturas famosas, obras arquitetônicas de edifícios históricos) e o desenvolvimento de tópicos de matemática presentes nessa visualização (ZALESKI FILHO, 2009; ZAGO; FLORES, 2010, SANCHES, 2015, STEIN; FONSECA, 2015,).

Nessas explorações, é comum que seja dado destaque a relações matemáticas como a Razão Áurea e a Sequencia de Fibonnaci, temas que podem ser considerados clássicos no que se refere a ligação entre Matemática e Beleza (LIVIO, 2008, CELLUCCI, 2015).

Entretanto, no ensino de Artes, além do conhecimento das obras da chamada "alta cultura", é o aluno que faz arte, que produz cultura. Não se trata da busca por um ideal de beleza, mas de colocar em jogo a criação, a crítica, a expressão, a imaginação, a sensibilização e a sociabilização.

Já no estudo da Matemática, não parece ser assim. Quando se está procurando contemplar a matemática apenas em obras de arte acabadas, a perspectiva é a de considerar uma Matemática pronta, que o aluno não tem que construir pois já é apresentada como acabada.

Mas e a criação, a sensibilização, a crítica e a sociabilização na Matemática, como ficam? Que papel a reação estética, típica da Arte, teriam na construção da Matemática? De que maneira a intuição e as emoções podem servir de guia para a investigação Matemática?

Nesse artigo apresentamos algumas reflexões com base no conceito de empatia, originado da experiência estética, estendido aos aspectos da criatividade, da imaginação e da abertura para o outro e seu pensar. Consideramos, assim, a relação entre Arte e Matemática no que se refere ao processo pelo qual a intuição guia a criação Matemática, tanto na pesquisa quanto na sala de aula, na resolução de problemas. 


\section{Beleza E Matemática Pronta}

As crenças e as formas de ver a Matemática influenciam a maneira como ela é ensinada (CURY, 1994). Por isso, examinar crenças sobre a relação entre Arte e Matemática pode ajudar a refletir sobre o ensino de Matemática.

Bertrand Russell (1872-1970), filósofo e matemático, afirmava: “A Matemática, vista corretamente, possui não apenas verdade, mas também suprema beleza - uma beleza fria e austera, como a da escultura" (RUSSELL, 1919/1951). O contexto da afirmação é o sistema filosófico de Russell, o Logicismo, corrente do pensamento matemático surgida no final do século XIX. A sentença relaciona os conceitos de verdade e de beleza. No Logicismo, a ideia de verdade em matemática está ligada a ideia da demonstração segundo a lógica formal:

O Logicismo, iniciado por Frege e retomado por Russell, pretende mostrar que a Matemática pode reduzir-se à Lógica. Em síntese, a teoria logicista está dividida em duas proposições: a) todo conceito matemático pode ser definido em termos de conceitos lógicos; e b) os enunciados matemáticos verdadeiros podem ser demonstrados a partir de princípios lógicos (CURY, 1994, p. 52).

Nesse modelo, "verdade" em Matemática é um termo associado a ideia de demonstração lógica. A beleza da Matemática viria dessa mesma forma de identificar afirmações provadas logicamente com verdade. Para quem possui essa visão "correta" da matemática - do ponto de vista do logicismo - ela revelaria sua beleza suprema. Não é por acaso que a beleza considerada por Russell tenha essas características: fria e austera, como em uma escultura.

Nesse sentido, a beleza da Matemática estaria ligada a apreciação que se pode fazer da construção de demonstrações de teoremas, em que seria necessário ver como cada parte se relaciona com as demais e com o todo. Isso exigiria, obviamente, compreensão da Matemática que se deseja apreciar, e assim a beleza estaria diretamente ligada à razão. Ou seja, apenas quem compreendesse matemática poderia apreciar sua beleza. Nesse sentido afirma Cellucci (2015):

Apreciar a beleza matemática exige apreender as ideias envolvidas de uma maneira que revele a relação das partes umas para as outras e para o todo, e isso é algo que uma formação pobre não pode fornecer (CELLUCCI, 2015, p. 345).

Essa associação entre compreensão e beleza remete ao Racionalismo. O movimento logicista foi influenciado pelo pensamento racionalista de Platão (século IV a. C.). Do Racionalismo de Platão, com sua valorização da razão em detrimento de outros aspectos do 
conhecimento, derivaria essa visão da beleza da matemática associada a um conjunto estático de teoremas e demonstrações.

Uma vez que, para Platão, a beleza carregava sempre um aspecto intelectual, seria absurda a existência de "um todo privado de intelecto que fosse mais belo do que um todo com intelecto”(PLATÃO, 2011, p.98). Desse modo, considerando a Matemática como corpo de "verdades" lógicas, sua beleza seria a maior de todas as belezas (ZEKI, ROMAYA, BENINCASA \& ATIYAH, 2014).

Para o platonismo, a beleza da Matemática estaria ligada a sua perfeição quase inalcançável: uma beleza para ser contemplada de certa distância, a fim de perceber a relação de cada parte com o todo. Ao relacionar matemática com uma forma estática de arte - a escultura - a sentença de Russell associa beleza tanto ao aspecto estático da Matemática pronta, sistematizada, quanto ao que em Arte se denomina de "alta cultura", ou "grande arte": a produção artística que resulta em uma obra de arte acabada, uma manifestação concreta como uma pintura, uma escultura ou uma sinfonia (ORTIZ, 2008).

De fato, é essa relação entre matemática e as formas de arte rígidas, prontas e acabadas, como esculturas, pinturas, obras arquitetônicas, que parece estar presente em diversos estudos que procuram relacionar Arte e Matemática, como os descritos em Le Lionnais (2004), nos capítulos Beleza e Matemática e Arquitetura e espírito matemático (esse último escrito pelo arquiteto Le Corbusier).

Essa forma de relacionar Arte e Matemática parte da associação entre obras prontas e estáticas com uma Matemática também pronta e estática, como aquela expressa por fórmulas. O elogio da beleza da Matemática com referência a suas fórmulas sintéticas, em si expressões de pura arte, revelaria a influencia do platonismo. A valorização da capacidade de sintetizar resultados que a matemática possui a faz semelhante, de certa maneira, a literatura, na qual obras poderiam ser consideradas "belas" por conseguirem exprimir o maior número de ideias com o menor número de palavras. Analogamente, teoremas e definições matemáticas seriam expressão do belo, pela sua capacidade única de síntese.

A beleza matemática está relacionada com a simplicidade das ideias e das demonstrações matemáticas, a sua inter-relação e as suas potencialidades de conexão com várias áreas da matemática, o seu carácter unificador, a sua maior generalidade, etc (OLIVEIRA, 2002, p.33).

Uma relação entre números essenciais à matemática, como a identidade de Euler, seria então uma fonte típica fonte de experiência estética nesse sentido:

$$
1+e^{i \pi}=0 \text {. }
$$


Assim se justificaria que a contemplação de um resultado como a fórmula acima teria a capacidade de provocar uma reação estética de maior ou igual intensidade que apreciar uma música, escultura ou pintura. Mas para uma pessoa que não faz a menor ideia do que essa fórmula representa, ainda assim ela poderia ser considerada a expressão do belo? Para o logicismo, aparentemente a resposta seria não, pois a Matemática, para ser bela, precisaria ser "vista corretamente". Seria preciso entender Matemática para apreciar sua beleza. Será?

No caso das Artes, não parece necessário “entender" para apreciar a beleza de uma obra artística. O conhecimento sobre o nome do pintor, o movimento artístico ao qual a obra pertence, os materiais utilizados pelo artista etc, não teriam um papel muito importante no julgamento estético. Por exemplo, a reação estética diante de uma obra como a pintura clássica Rosa e Azul de Renoir (1881), seria restrita aos conhecedores da pintura história dessa pintura, ou a algum outro relato associado a ela?

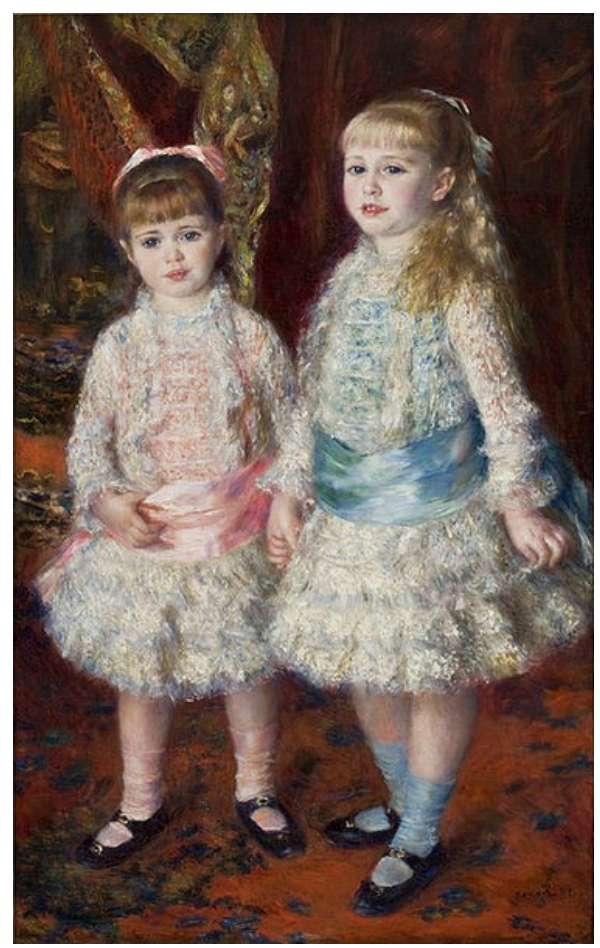

Figura 1 - Rosa e Azul, de Renoir (1881) Fonte: https://pt.wikipedia.org/wiki/Ficheiro:Renoir_Mlles_Cahen_d_Anvers.jpg

Pois bem, embora o sentido estético das pessoas possa ser desenvolvido por sua formação, e a escola tenha um papel importante nesse sentido (PELAES, 2015), a fruição estética das obras de arte depende de cada espectador e não está atrelada exclusivamente a sua formação e estudos em Artes.

No caso da Matemática, o fenômeno estético se daria da mesma forma? Ou a apreciação da beleza de uma expressão matemática dependeria exclusivamente do grau com 
que o espectador entende a matemática ali envolvida?

No que se refere apenas a esse aspecto rígido, pronto, acabado da matemática em sua expressão formal, esse aspecto visual em que símbolos matemáticos se associam para expressar algum resultado final, aparentemente a reação estética não depende totalmente da compreensão do que se está vendo.

A presença da experiência estética pela contemplação de fórmulas foi objeto de estudo de uma pesquisa na área de neurociência (ZEKI, ROMAYA, BENINCASA \& ATIYAH, 2014). Nessa pesquisa, a experiência da beleza na visualização de fórmulas matemáticas foi estudada por meio dos fenômenos neurais correlatos. Por um lado, a pesquisa visava verificar se reação estética diante das fórmulas matemáticas seria a mesma, do ponto de vista neurológico, da que se tem diante da contemplação de obras de arte visuais. E por outro, a pesquisa poderia mostrar um pouco da relação entre compreensão e reação estética em matemática.

Para isso, foram estudadas as reações de dois grupos: dezesseis matemáticos (considerando matemáticos alunos de pós graduação e pós doutorado de universidades de Londres) e outras doze pessoas consideradas não-matemáticas. Cada um dos sujeitos classificou 60 fórmulas matemáticas como belas ou feias, atribuindo-lhes certas notas (a fórmula que recebeu as melhores notas foi a identidade de Euler).

Embora o ideal fosse comparar os resultados da apreciação estética da "beleza" das fórmulas do grupo dos matemáticos com um grupo de sujeitos não instruídos em matemática, isso não se apresentou viável. As pessoas do segundo grupo tinham pelo menos algum conhecimento de matemática da escolaridade básica.

Nesse processo, constatou-se que a experiência estética suscitada pela contemplação das fórmulas é a mesma experiência estética suscitada pela música e pela beleza visual, do ponto de vista neural, no caso do grupo dos matemáticos. Isso confirma o que já era esperado, que pessoas instruídas em matemática, quando defrontadas com resultados matemáticos que consideram belos, têm reação estética semelhante àquela que experimentam quando contemplam obras de arte.

Restava então saber se os não-matemáticos, que não entendiam o significado de quase nenhuma das equações apresentadas, também iriam considerar as equações bonitas como pinturas.

Pois os resultados mostraram que sim - eles acharam algumas das fórmulas muito bonitas. Ao classificar uma equação como bela, provavelmente o fizeram com base nas 
qualidades formais das expressões, como a forma como os símbolos estavam dispostos, se possuíam simetria etc. Compreensão e senso estético estão aqui dissociados, pois entre as equações que os sujeitos manifestavam compreender menos, houve mais reação estética.

Com isso, concluíram que "algumas combinações de formas são mais esteticamente agradáveis do que outras, mesmo que não sejam "compreendidas" cognitivamente" (ZEKI, ROMAYA, BENINCASA \& ATIYAH, 2014, p. 10).

Pessoas que não faziam ideia do significado de determinadas fórmulas, as acharam bonitas. Isso por si só não mostra que reação estética não tenha relação com a compreensão, mas mostra que uma não depende estritamente da outra.

A experiência estética da beleza em contemplação de formulas matemáticas representaria o caso mais extremo da beleza que dependeria, em tese, da aprendizagem e da cultura. Se essa experiência da beleza matemática, assim como a experiência da beleza musical e visual, acionassem a mesma área do cérebro, então talvez existisse, do ponto de vista neurológico, "uma qualidade abstrata para a beleza que é independente da cultura e da aprendizagem" (ZEKI, ROMAYA, BENINCASA \& ATIYAH, 2014, p.10).

Pode-se concluir que a beleza da matemática não estaria apenas associada ao aspecto racional do seu conhecimento, como pensavam Platão, Descartes e Russell. A experiência estética com a matemática indicaria que é possível relacionar Matemática e Arte em maior grau, e haveria relações entre o ensino de Matemática e o de Artes que poderiam ser mais exploradas.

Partindo do fato de que a reação diante da Matemática, mesmo sem ser "vista corretamente" como diria Russell, pode estar associada a beleza, então o desenvolvimento dessa capacidade estética poderia se dar no processo de construção da matemática, em que a compreensão se vai constituindo aos poucos.

\section{Beleza E Matemática Em Construção}

A pesquisa sobre a correlatos neurais na experiência da beleza matemática citada acima parece ter confirmado a afirmação de que "qualquer coisa pode ser um objeto estético se estabelecemos ante ele uma atitude estética" (PEREIRA, 2011, p.115). Ou seja, se forem apresentadas fórmulas matemáticas para qualquer pessoa com alguma escolaridade, ela poderia ter uma reação estética por estabelecer uma atitude estética diante daquelas formulas, já que lhe foi pedido para classificar as fórmulas como bonitas ou feias. 
Lembro-me de que, ao pescar com meus filhos pequenos, costumávamos classificar inicialmente os peixes como grandes ou pequenos, mas como essa classificação gerava, às vezes, conflitos e comparações (disputas para saber quem pescou mais ou quem pescou o maior), partiamos para a classificação estética. Embora todas as tilápias fossem bastante parecidas, era comum ouvir expressões como essas: "Olha, pai, que peixe bonito!" ou "Nossa, filha, que peixe mais lindo!".

Compreender que é possível ter uma atitude estética diante de algo que não tradicionalmente se classificaria como "belo" parece ser importante para a Matemática - tanto para sua pesquisa, quanto para seu aprendizado.

A percepção da beleza fria da Matemática pronta, como aquela expressa por fórmulas, seria apenas uma das formas de relacionamento estético com esse campo do conhecimento.

A experiência que podemos ter com uma peça de Bach, com uma música de Luis Gonzaga, com uma canção infantil, com o canto de um pássaro ou com o ruído de um trem não têm o mesmo valor. Sim, todas podem constituir-se experiências estéticas. Mas é inegável que há uma grande diferença de valor entre elas (PEREIRA, 2011, p.120).

A "suprema beleza", associada por Russell a estrutura estática da matemática, não seria a única forma de relacionamento estético com a Matemática. Quando ele chama a atenção para uma "beleza fria e austera, como a da escultura", parece eclipsar o lado dinâmico da beleza da matemática em construção.

Para além das demonstrações elegantes de teoremas e das formulações maravilhosas da Matemática, que podem ser consideradas belas até por quem não faz ideia do que tratam, existiria uma beleza na própria busca da construção matemática - tanto por parte dos pesquisadores, quanto por parte dos estudantes. A beleza não estaria apenas nos resultados finais, mas na atividade investigativa:

A actividade investigativa dos alunos, em todas as suas vertentes e fases, deve ser apreciada esteticamente. A beleza matemática associada a uma intuição fecunda, a uma ideia inesperada, a uma boa estruturação lógica, etc., não deve ser subordinada a critérios utilitaristas de obtenção de resultados a todo o custo." (OLIVEIRA, 2002, p.33)

Com a compreensão estética da matemática, os próprios alunos poderiam trabalhar melhor com a matemática, aprendendo a "sentir" por que determinada definição é mais aceita do que outras, por que determinadas demonstrações não são boas o suficiente e devem ser refeitas, por que determinado raciocínio não está bem formulado matematicamente. "A estética, ligada à perfeição das demonstrações, pode funcionar como um critério de eliminação de ideias matemáticas.” (OLIVEIRA, 2002, p.33) 
Nesse processo, tanto no meio educacional quanto no ambiente da pesquisa em Matemática, a beleza teria um papel muito importante:

A beleza matemática pode ter um papel no contexto da descoberta, pois pode nos orientar na escolha da hipótese a considerar e a qual desconsiderar. (CELLUCCI, 2015, P. 353)

O filósofo e matemático Henri Poincaré (1854-1912) defendia uma visão de estética ligada à matemática bem diferente de Russell. Não era tanto a beleza da matemática pronta que o interessava, com todas as suas possíveis aplicações, mas a forma como os cientistas construíam o conhecimento (POINCARÉ, 2008). Nesse sentido, era a beleza do fazer e aprender Matemática que mais lhe interessava: a Matemática em construção.

A ciência tem tido aplicações maravilhosas; mas uma ciência que só tivesse em vista as aplicações já não seria ciência, seria apenas culinária. Não existe ciência senão a ciência desinteressada (POINCARÉ, 2008, p. 269).

Poicaré acreditava que a estética seria como uma força que orientava os matemáticos para que suas pesquisas percorressem caminhos fecundos. Para ele, a estética estava ligada a forma como se conhece, como se aprende, como se constrói conhecimento, atividades em que se utilizam recursos diferentes do raciocínio dedutivo, usado para resolver formalmente as questões matemáticas (EBERLE, 2014).

A estética entraria no processo pelo qual os matemáticos "enxergam" determinados veios de investigação muito antes de descobrir a prova de possíveis resultados - aliás, muito antes mesmo de serem capazes de antever quais resultados poderiam surgir de determinada exploração.

Um senso bem desenvolvido de estética orienta os matemáticos para "ver" os melhores caminhos da pesquisa, muito antes de descobrir qualquer raciocínio dedutivo que justifique a sua exploração (EBERLE, 2014, p. 130).

A filosofia da matemática de Poincaré, inserida no movimento da filosofia da Matemática chamado de Intuicionismo, surgido no início do século XX, propunha que

(...) a Matemática é uma construção de entidades abstratas, a partir da intuição do matemático, e tal construção prescinde de uma redução à linguagem especial que é a Lógica ou de uma formalização rigorosa em um sistema dedutivo (MACHADO, 1989, p. 40).

Nessa busca baseada na intuição, o Matemático não estaria perseguindo uma "verdade" em si a respeito de uma sentença, uma prova de que um teorema é falso ou verdadeiro, mas algo além: uma compreensão do mesmo, uma espécie de iluminação ou posse de algo que vai além do próprio teorema em si. Ele não busca o belo, ele o encontra na contradição, no desafio, na dificuldade. 
Como após Poincaré pouco se escreveu sobre o papel gerador da estética na Matemática, em geral, quando se fala do tema, se associa Arte apenas com os resultados finais estáticos da Matemática.

Mas qual seria, então, a estética de uma Matemática ainda em fase de construção, de exploração, ainda sem resultados prontos, ainda em fase de aprendizagem? $\mathrm{Na}$ fase de pesquisa, assim como na fase de aprendizagem, os conceitos ainda não existem ou não estão claros. As relações entre as ideias ainda não estão visíveis. É o momento do indizível, do inusitado, do arrebatamento, da sensação vaga de falta de controle ou previsão, da contradição.

Mas a reação estética vem, precisamente, como ressaltava o cientista Lev Semenovitch Vigotski (1896-1934), da contradição de sentimentos. O pensamento de Vigotski apresentou muitas concepções criativas que tem servido para uma abordagem histórico-cultural da psicologia, principalmente tomando-se como base suas obras mais conhecidas, como $A$ formação social da mente: o desenvolvimento dos processos psicológicos superiores (VIGOTSKI, 1991).

Já em uma de suas obras menos conhecidas, como a Psicologia da Arte, escrita em 1925, que foi seu primeiro trabalho a abordar a psicologia, ele apresenta abordagens originais sobre a sensibilidade estética. Ele defende como, por meio da contradição, ocorre a transformação de uma emoção em outra: “A lei da reação estética é uma só: encerra em si a emoção que se desenvolve em dois sentidos opostos e encontra sua destruição no ponto culminante, como uma espécie de curto-circuito" (VIGOTSKI, 1998, p.270). Desse modo, reações estéticas não são apenas provocadas por contemplações estáticas, mas por verdadeiros curtos-circuitos em nossas emoções.

Sendo assim, conseguimos inferir que a Arte é o objeto da Educação Estética, mas não como algo a ser apenas contemplado, mas sim como algo que provoca sensações epifânicas, através dos sentidos, como percepção do indizível e do invisível que vem daquela experiência, quando o sujeito se vê diante do inusitado ou num momento de arrebatamento, em que não há controle ou planejamento (DE LUCAS, ROSITO, 2018, p. 172).

Nesse sentido, a beleza da Matemática não estaria associada unicamente a expressão formal dos seus resultados, mas ao seu processo construtivo, com seus altos e baixos, o que a assemelharia a uma construção literária. A construção Matemática se daria como a construção de uma narrativa, em um processo não desprovido de emoções.

Os matemáticos são guiados por emoções, como a curiosidade em relação ao que percebem como os aspectos mais estéticos da matemática. As ideias e os métodos que os atraem emocionalmente provam ser os mais frutíferos. Sem 
tal envolvimento estético emocional, pode ser difícil para os matemáticos perseverar na investigação matemática extensa (EBERLE, 2014, p. 130).

Esse processo se daria sem necessária explicitação de questões estéticas, ou “instruções estéticas" a respeito da uma parte da matemática sobre a qual um matemático está interessado. O matemático segue sua intuição e dá conta assim do seu trabalho, sem necessidade de que alguém aponte para ele qualquer aspecto de beleza sobre o que está fazendo (PIMM, SINCLAIR, 2017). Nesse sentido, sua atividade de pesquisa é semelhante a de um romancista, cuja obra final acaba por se traduzir em um texto escrito em determinada língua, mas cuja arte não se resume a um conjunto de caracteres:

É certo que, para ler um romance, devo ser capaz de ver o texto a minha frente, mas dificilmente se poderia dizer que a minha experiência estética na leitura de um romance consiste em decifrar as palavras na página na minha frente. Nem eu, literalmente, vejo os fatos narrados na novela, eu apenas os imagino, e a imaginação é a capacidade de representar algo mesmo quando não está presente diante dos meus olhos. (CELLUCCI, 2015, p. 344)

A beleza da Matemática estaria, assim, muito ligada à capacidade de imaginar, necessária tanto para se fazer quanto para se aprender Matemática. Essa intuição, esse convite a imaginação e à criação, estaria no centro do processo de criação de conhecimento. "A criação não se faz a partir do nada. Ela pressupõe uma relação entre fantasia e realidade. Para criar, é preciso, de algum modo, entrar nos objetos da experiência” (BROLEZZI, 2015, p. 804).

Ao considerar a Matemática como processo de construção narrativo, percebe-se que a beleza, a reação estética, não se dá apenas em contemplar algo "bonito", limpo, pronto e acabado. Há beleza na Matemática também quando se percebe uma conexão inesperada e surpreendente de elementos diferentes (CELLUCCI, 2015). A história da Matemática revela as idas e vindas dos caminhos seguidos até se chegar a Matemática pronta e acabada, e esse caminho pode ser tortuoso e estressante. Ao estudar sua história, o que se obtém é essa visão da Matemática em construção (BROLEZZI, 2014). Existem diversos tipos de beleza, e a beleza da construção Matemática é também particular nesse sentido, de ser uma beleza como que imperceptível:

Claro, a beleza escultural, a beleza pictórica, a beleza musical, a beleza literária, a beleza matemática, etc., são diferentes tipos de beleza. Mas isso significa que existem diferentes tipos de beleza, mesmo no domínio da beleza derivada de fontes mais baseadas na percepção. (CELLUCCI, 2015, P. 344)

Então é preciso experimentar a especificidade do pensamento matemático para enxergar sua beleza oculta. Podemos traçar um paralelo entre ensino de Matemática e ensino 
de Artes. Em Artes não se incentiva a postura passiva de quem contempla obras prontas. Em Matemática é comum se colocar o aluno na condição de quem apenas contempla a Matemática pronta e limpa. Mas também poderia haver maneiras de fruição estética da Matemática.

Comentando o ensino de Artes proposto pelos Parâmetros Curriculares Nacionais (1997 e 1998), Pelaes (2015) afirma que o sentido da apreciação estética ali proposto

(...) apresenta-se como uma possibilidade ampla de análise, que abrange desde a percepção fenomênica, fundada na vivência cotidiana, como a percepção estética fruto de moldes e padrões culturais. Tal sensibilidade é concebida como uma abordagem em diferentes pontos de vista e não necessariamente supondo graus, a priori, progressivos de percepção estética (PELAES, 2015).

No caso do ensino de Artes, propõe-se uma diversificação de atividades de modo a favorecer a capacidade criativa do aluno. São incentivados o uso de materiais diferentes e o estabelecimento de relação entre artes e os diversos conhecimentos que podem ser a ela associados, "entendendo a aula de arte e a área como fonte inesgotável de aprendizado, semelhante às outras áreas do currículo" (PELAES, 2015).

A relação entre ensino dessas áreas, Artes e Matemática, pode ser reforçada ao se considerar a relação entre fazer arte e fruir das obras de arte prontas. A Arte é uma área de conhecimento, como as demais do currículo escolar. Nela são propostos estudos sobre questões estéticas e temas da história da arte, considerando que essa atividade de apropriação cultural desenvolve a sensibilidade estética e o espírito crítico do aluno em relação a arte:

A convivência com bens culturais e com os códigos de interpretação desses bens, pode encontrar na escola e nas aulas de arte, um meio de apropriação do conhecimento de diferentes culturas, reinterpretadas num processo de construção de uma sensibilidade estética e de desenvolvimento de um olhar crítico em relação a arte. (PELAES, 2015)

O contato com a história da arte e com as formas de interpretar os bens culturais desenvolvidos pela humanidade em suas diferentes culturas pode ajudar a desenvolver formas de apreciação estética e um olhar crítico em relação à arte. No que se refere a Matemática, o uso da história também pode servir para perceber a forma como a matemática é construída, indo-se além da percepção de uma matemática pronta e acabada.

Dessa forma, além de aprender conteúdos matemáticos e suas formas históricas de construção, a sala de aula de Matemática poderia se transformar um pouco em uma sala de Artes, na qual os alunos aprendem a cultura matemática participando de seu processo de criação. 


\title{
4 Beleza, Matemática E Empatia
}

Em sua obra Arte e conhecimento: ver, imaginar e criar, Bronowski (1974) discorre sobre o processo de criação científica em geral, e a relação desse processo com a Arte. Ele destacava o papel da imaginação no processo de aprendizado, já que "penetramos com a imaginação na experiência das outras pessoas" (BRONOWSKI, 1974, p. 158).

Quando se debruçava para explicar a lógica da pesquisa científica, o filósofo da ciência Karl Popper (1902-1994) utilizou o termo Einfühlung, utilizado pelo físico Albert Einstein (1879-1955) para descrever o processo de criação científica (POPPER, 2004). Popper afirmava não haver um método lógico de criar ideias novas:

\begin{abstract}
Minha maneira de ver pode ser expressa na afirmativa de que toda descoberta encerra um "elemento irracional" ou "uma intuição criadora", no sentido de Bergson. De modo similar, Einstein fala da "busca daquelas leis universais (...) com base nas quais é possível obter, por dedução pura, uma imagem do universo. Não há caminho lógico", diz ele, "que leve a essas (...) leis. Elas só podem ser alcançadas por intuição, alicerçada em algo assim como um amor intelectual (Einfühlung) aos objetos de experiência" (POPPER, 2004, p. 32).
\end{abstract}

A palavra da língua alemã Einfühlung significa sentir dentro ou sentir em, e sua criação é atribuída ao filósofo Robert Vischer (1847-1933) que a utilizou em 1873 para descrever a experiência estética (GALLESE, 2003). Inicialmente, o termo se referia a projeção de um observador para dentro de um objeto contemplado. Por meio da Einfühlung, “[...] propriedades subjetivas como nobreza, elegância e poder podiam ser sentidas como se pertencessem às próprias obras de arte, tal como se estas fossem seres com vida" (SAMPAIO; CAMINO; ROAZZI, 2009, p. 213).

Mais tarde, filósofo alemão Theodor Lipps (1851-1914) estendeu o conceito de Einfühlung para as relações interpessoais, utilizando-o para descrever movimento de um indivíduo cujo pensamento se projeta para o interior de outro. O próprio Lipps teria sugerido a versão grega empatheia para o termo (DE WAAL, 2010) que depois deu origem à palavra empatia em diversas línguas. Mas em grego, empatheia significava apenas paixão, em um sentido de sofrimento ou enfermidade, e em grego moderno a palavra $\varepsilon \mu \pi \alpha ́ \theta \varepsilon \imath \alpha$ (empátheia) significa o oposto de empatia: ódio ou forte aversão. Principalmente após os trabalhos do psicólogo inglês Edward Bradford Titchener (1867-1927), que utilizou o termo em inglês empathy em 1909 para traduzir Einfühlung, a palavra empatia adquiriu o significado moderno de colocar-se no lugar do outro.

O construto empatia pode, assim, ser utilizado para se compreender como o 
Matemático entra no tema que pesquisa, e constrói seu conhecimento seguindo sua paixão intuitiva. E essa forma de participar da criação em matemática não se precisa ficar restrita apenas à pesquisa científica: ela pode entrar também na sala de aula.

A atividade de resolução de problemas é central no fazer matemático (POLYA, 1977). A sala de aula de Matemática é, em boa parte, um ambiente em que se resolvem problemas matemáticos.

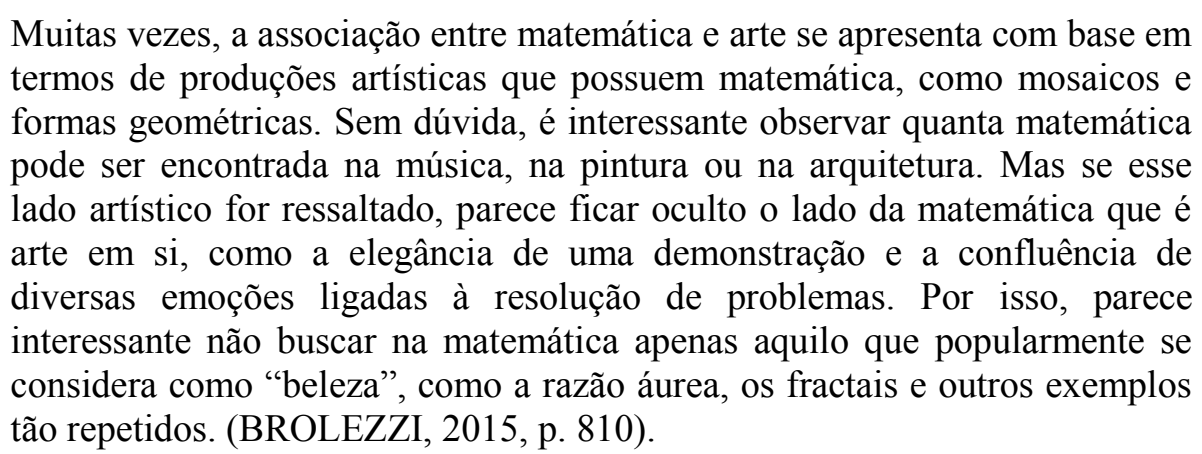

Observe-se que o foco do que ocorre em uma sala de aula de Matemática elementar é a Matemática em construção. Daí que a criatividade possa estar livremente em ação. Gontijo (2007) estudou as relações entre criatividade, criatividade em Matemática e motivação em Matemática. Embora não tenha abordado a relação entre Matemática e Arte, apontou que, na resolução de problemas, é desenvolvida a sensibilidade estética.

As formas de pensamento ligadas a resolução de problemas, com suas contradições e criações, podem reforçar a associação entre matemática e arte, para além da simples contemplação:

Assim, alguns aspectos que contribuem para a descrição do processo criativo, tais como imaginação, originalidade, flexibilidade, fluência, inventividade, engenhosidade, elaboração, espontaneidade, sensibilidade, senso estético e atitude questionadora podem estar incluídos entre os objetivos educacionais (GONTIJO, 2008, p. 3)

Enriquecer o ambiente da sala de aula de Matemática por meio da resolução de problemas ambientada em uma cultura matemática mais ampla significa permitir aos alunos se aproximar do fazer matemático criativo. Como afirmava Vigotski, "ensinar o ato criador da arte é impossível, isto não significa, em absoluto, que o educador não pode contribuir para sua formação e manifestação" (VIGOTSKI, 1998, p.325).

Segundo esse autor, a criatividade e a imaginação precisam ser cultivadas na escola, como se cultivam flores em um jardim. De maneira geral, a imaginação nunca vem do nada, e "seria um milagre se a imaginação inventasse do nada ou tivesse outras fontes para suas criações que não a experiência anterior" (VIGOTSKI, 2009, p.20). 
Por isso podemos acreditar que

(...) a imaginação sempre constrói de materiais hauridos da realidade. É verdade que [...] a imaginação pode criar, cada vez mais, novos níveis de combinações, concertando, de início, os elementos primários da realidade. [...] A atividade criadora da imaginação depende diretamente da riqueza e da diversidade da experiência anterior da pessoa, porque essa experiência constitui o material com que se criam as construções da fantasia. Quanto mais rica a experiência da pessoa, mais material está disponível para a imaginação dela" (VIGOTSKI, 2009, p.21-22).

A imaginação criativa pode ser desenvolvida se forem disponibilizados um espaço e um tempo para tal. É possível desenvolver indivíduos que sejam imaginativos e matematicamente criativos, mas para isto é preciso lhes fornecer elementos para que esta criatividade se desenvolva. É por meio do enriquecimento da experiência no campo matemático que se forma a criatividade.

Quanto mais rica a experiência, mais rica deve ser também a imaginação. [...] A conclusão pedagógica a que se pode chegar com base nisso consiste na afirmação da necessidade de ampliar a experiência da criança, caso se queira criar bases suficientemente sólidas para a sua atividade de criação (VIGOTSKI, 2009, p.22-23).

A ampliação desta experiência se potencializa pela socialização. Não basta o professor mostrar métodos e percursos para se resolver problemas e pedir para que os alunos os reproduzam em problemas parecidos. É na troca de experiências que se aprendem as várias formas como um problema pode ser resolvido, fugindo da ideia da receita culinária.

Nessa troca de experiências em que, por meio da imaginação, se pode penetrar na experiência de pensamento alheia (BRONOWSKI, 1974), o conceito de empatia pode ser utilizado.

Empatia, a capacidade humana de se colocar na perspectiva do outro e assim conhecêlo incluindo suas ideias e sentimentos, seria "uma forma de se ampliar o universo pessoal, por meio da arte, fenômeno a partir do qual o homem pode completar sua vida, incorporando experiências alheias" (BROLEZZI, 2015, p.802).

$\mathrm{Na}$ atividade cotidiana de resolução de problemas, que envolve um estilo de aula dialogada em que se investiga um tema matemático e se fazem ligações entre conceitos, ideias e intuições aparentemente dissociadas, a discussão se dá entre os alunos e entre esses e o professor:

Nesta forma de trabalhar com problemas, os alunos são levados a discutir, a ouvir os outros, a entender diversas formas de pensar. Cria-se um ambiente de empatia, essencial na relação professor-aluno-conhecimento. O processo de entrar no lugar do outro, no sentido de vivenciar formas diferentes da própria maneira de pensar, parece ser bastante incentivado (BROLEZZI, 
2015, p.806).

Para que os alunos tenham experiência com a Matemática, aproveitando-se do paralelo desta com a Arte, é preciso que não sejam oprimidos por um ambiente de cobrança e crítica paralisantes, impróprio para o desenvolvimento crítico. Paradoxalmente, parece adiantar pouco, para que os alunos possam ver a estética que existe na Matemática, que sejam obrigados de modo desagradável a estudar exemplos clássicos que relacionam Arte e Matemática, como a razão áurea ou os fractais. Também não parece ter qualquer resultado positivo que os alunos sejam afogados com discursos visando mostrar como determinada fórmula, relação ou demonstração seria elegante ou esteticamente bela. Não é assim que funciona o ensino de Arte. A expressão artística é, obviamente, uma expressão, e o que está expresso nem sempre é visível. Expressividade só existe com liberdade.

Para se formar um bom e autêntico artista "não é o caso (deste) de dominar alguma fórmula nem de representar ou reproduzir fielmente um modelo" (EUSSE, BRACHT \& ALMEIDA, 2016, p.16). Embora as técnicas artísticas sejam sofisticadas e cada vez mais computacionais, sabe-se que a criação artística exige não apenas uma técnica bem aplicada, mas criatividade, estética e emoção.

Considera-se que a criatividade possa ser desenvolvida dentro da escola, mas depende em grande parte da participação da vontade do aluno. Um aluno que sente repulsa à matemática não irá se empenhar a resolver um problema sozinho, pois provavelmente desistirá no primeiro obstáculo. No caso do pesquisador em Matemática, é provável que a vontade de estudar determinado problema venha de seu próprio interior, o que nem sempre ocorre no caso do estudante. Então é preciso que, para entender a matemática, o aluno tenha uma atitude positiva em relação a ela.

Se a atitude é permeada de emoção positiva em relação ao estudo da Matemática, tudo isso parece estar muito além do alcance das capacidades do professor. Não é possível obrigar alguém a gostar de matemática. Entretanto, professores com atitudes negativas em relação à matemática, provavelmente transmitirão estas atitudes à seus alunos (FARIA, 2006). Dessa maneira, o aluno gostar ou não de matemática depende em parte da atitude que seus professores têm em relação a ela. Assim, se torna fundamental na formação de professores que sejam desenvolvidas atitudes positivas em relação à matemática.

A Matemática é área altamente complexa do conhecimento humano. Para estudá-la, exige-se muito esforço e dedicação. As diversas áreas desenvolvidas dentro da Matemática, em particular nos últimos três séculos, a tornaram extremamente específica e complexa. Desse 
modo, rotular quem tenha dificuldade com Matemática não parece atitude que favoreça o desenvolvimento dessa área.

O ambiente dos cursos de Licenciatura em Matemática, nos quais se dá a formação de professores que irão atuar em diversos níveis de escolaridade, precisa ser sobremaneira não catastrófico. Deve ser um ambiente em que seja incentivado o gosto pela Matemática e o desejo de quebrar preconceitos e atrair pessoas para essa fundamental área de conhecimento:

(...) já no início do curso, (...) [deve-se] estimular o entusiasmo pela matemática e também o desejo de ensinar. (...) Deve haver uma preocupação com o modo como os professores universitários ensinam e como os estudantes de licenciatura aprendem (FARIA, MORO \& BRITO, 2008, p.253).

Para que professores do ensino básico vejam a beleza da matemática e possam, assim, fazer com que seus alunos gostem dela, e preciso que, por sua vez, os professores de cursos de formação de professores demonstrem a beleza prática que existe na construção desse conhecimento humano. Não se trata, como já foi dito, de insistir em tentar explicar de onde vem a beleza estética da matemática. Pelo fenômeno da empatia, professores que gostem do estudo da matemática ajudam a revelar essa característica tão intima da construção matemática.

Ou seja, o aluno de licenciatura poderá encontrar a beleza da matemática em sua própria intuição e tornar-se, assim, um professor mais apaixonado. Por sua vez, seus futuros alunos irão produzir seus pensamentos matemáticos enxergando a beleza que há nessa prática criativa.

Infelizmente, ao que parece, a empatia não é ainda tratada em matéria alguma de curso de formação de professores de matemática.

\section{Conclusão}

Para Vigotski “a arte é o social em nós” (VIGOTSKI, 1998, p.315). A arte, além de nos emancipar como indivíduos, é o meio de que nos valemos para nos incorporar na sociedade. É pela arte que nos transformemos. A partir desta transformação, transforma-se a sociedade.

Ver a matemática como uma forma de Arte pode mudar a abordagem do seu ensino. O ensino de matemática deixa de ser o ensino de uma técnica, método ou linguagem, para ir incorporando algumas características do campo artístico.

Relacionar o ensino e aprendizagem da Matemática com o de outras áreas da educação 
humana pode ajudar a refletir sobre o papel transcendente da educação, como propunha Vigotski. A partir da perspectiva histórico-cultural de Vigotski, Albarrán (2017), estudou o desenvolvimento de bailarinas com deficiência visual. Nessa perspectiva, considera-se que o aprendizado depende do desenvolvimento, e o desenvolvimento também depende do aprendizado. Quanto mais o ser humano aprende mais ele se desenvolve, e por consequência desse desenvolvimento amplia-se sua capacidade de aprendizagem. Desta forma, tornar-se uma bailarina para uma pessoa com baixa ou nenhuma visão depende de estímulos que propiciem aprendizado e desenvolvimento. A Arte tem esse papel no processo de emancipação humana:

(...) a arte emancipa o indivíduo de sua condição cotidiana por promover um tipo de experiência que muda qualitativamente os modos de percepção de expressão e representação. Por isso, a vida e a arte estão intrinsecamente relacionadas no processo de desenvolvimento humano (ALBARRÁN, 2017, p.45).

Assim, o que a princípio seria apenas uma forma de recreação e divertimento para as estudantes de balé de baixa visão, acabou por permitir uma redescoberta pessoal, um novo olhar sobre a deficiência e sobre si mesmas. Todas chegaram a vivenciar, em grau maior ou menor, através da dança, o que Vigotski chamou de perejivanie, "um processo próprio da vida humana, e pode ser entendida como um acontecimento de forte carga emocional capaz de produzir mudanças profundas na vida de uma pessoa real” (ALBARRÁN, 2017, p. 103).

A deficiência deixou de ser uma limitadora das capacidades destas mulheres. A partir de aulas que respeitavam a deficiência e, com isto, transcorriam com uma metodologia diferente daquelas feitas para pessoas videntes, as bailarinas puderam se desenvolver plenamente, de tal forma que muitas acabaram tornando-se bailarinas profissionais.

Além das próprias bailarinas, a dança transformou também aqueles que participaram. O público, ao assisti-las, observava a arte antes das deficiências. Festivais que antes se recusavam a deixá-las se apresentar, depois passaram a acolhê-las. Nesse processo, "as mudanças que marcam as vidas das bailarinas cegas ou com baixa visão transformam não apenas elas mesmas, mas toda uma sociedade ainda envolta em preconceitos" (ALBARRÁN, 2017, p.171).

Ao adentrar em suas salas de aula, muitos professores de Matemática podem sentir-se cansados e desalentados diante da tarefa que se lhes afigura como profundamente ingrata: pensar em como fazer alunos gostarem do que nem enxergam. Talvez não se trate de fazer gostar, mas de fazer experimentar, de promover vivências. A repulsa pela matemática é muitas vezes originada de uma experiência que a pessoa teve com essa em algum momento de sua 
vida. Pois então a atração por ela pode também derivar desse contato, de uma perejivanie transformadora.

A crença de que Matemática é assunto apenas para aqueles que possuem certo dom individual é muito forte. Claro que em qualquer área, artística, esportiva ou científica, há dons, facilidades e dificuldades (algumas dificuldades bastante especiais, inclusive). Mas imaginar que Matemática é área de atividade essencialmente individual é um mito que deve ser combatido. A construção da Matemática é processo essencialmente colaborativo.

A pesquisa em Matemática no Brasil é muito desenvolvida. O país está na elite da matemática mundial há muito tempo e, desde o início de 2018, participa do restrito Grupo 5, que reúne as nações mais desenvolvidas em pesquisa matemática (Alemanha, Brasil, Canadá, China, Estados Unidos, França, Israel, Itália, Japão, Reino Unido e Rússia) (IMPA, 2018).

Não há dúvida de que isso ocorre devido ao talento dos Matemáticos que trabalham no Brasil. Mas o que caracteriza o progresso da produção científica atual é a capacidade de colaboração com colegas de todo o mundo (IMPA, 2018). Qualquer matemático precisa de empatia para entender as ideias dos demais pesquisadores, pois é essa leitura da mente dos demais que permite que ele identifique erros e possa dar sua contribuição que, por sua vez, precisa ser compreendida pelos demais.

Embora a malha de cooperação intensa dos matemáticos faça com que os resultados da pesquisa nessa área se assemelhem a um balé bem orquestrado, em que cada um necessita dos demais para em conjunto apresentarem sua arte sublime, muito esforço fica oculto no caminho da construção matemática.

Até se chegar a essas apresentações finais - as publicações - a produção matemática passa pelos caminhos incertos dos esboços, rascunhos, e ensaios, nos quais são necessárias muitas ações de auxílio (ou socorro) mutuo, para a realização de cada um dos passos necessários para que as teorias se harmonizem em um todo coerente.

É com esse espírito de ensaio geral que a Educação Matemática, cujo foco é a construção do conhecimento matemático pelos alunos, pode ser campo também de transformação de nós mesmos, professores, dos nossos alunos e de nossa sociedade. Nesse sentido, os efeitos do contato com a Matemática seriam semelhantes aos efeitos do contato com a Arte:

O contato com a arte faz pensar, refletir e agir, desenvolvendo no aluno um sentimento de humanidade, de ligação com si mesmo e com o outro. Estimula a resposta, a revolta, a negação, o acolhimento; o contrário da catatonia, da ignorância e da aceitação pura do mundo e das ideias que lhe forem impostas. A solidariedade, o senso crítico, o respeito às diferenças e a 
compreensão das necessidades do outro são de extrema importância dentro de sociedades democráticas (MELLO, 2017.p. 42).

Assim, a Matemática, abordada como Arte, além de nos oferecer uma melhor compreensão sobre si, também abre oportunidades para a criação de um melhor ensino e, futuramente, de um melhor ser humano para uma sociedade mais justa e igualitária.

\section{Referências}

ALBARRÁN, P. A. O. O ofício da dança e a bailarina cega ou com baixa visão: um estudo a partir da perspectiva histórico-cultural. 2017. xii , $198 \mathrm{f}$. Tese (Doutorado em Processos de Desenvolvimento Humano e Saúde)—Universidade de Brasília, Brasília, 2017

BROLEZZI, A. C. A arte de contar: história da matemática e educação matemática. São Paulo, Editora Livraria da Física, 2014

BROLEZZI, A. C.. Criatividade, empatia e imaginação em Vigotski e a resolução de problemas em matemática. Educação Matemática Pesquisa. v. 17, p. 791-815. 2015.

BRONOWSKI, J. O senso comum da Ciência. São Paulo: Edusp/Itatiaia, 1974

BROWN, S. Mathematics and humanistic themes: sum considerations, Educational Theory 23(3), 191-214. 1973

CELLUCCI, Carlo. Mathematical beauty, understanding, and discovery. Foundations of Science, v. 20 , n. 4, p. 339-355, 2015

CURY, H. N.. As concepções de matemática dos professores e suas formas de considerar os erros dos alunos. Tese de Doutorado. Porto Alegre: UFRGS, 1994.

DE LUCAS, G. A.; ROSITO, M. M. B. Experiência estética e Educação Matemática: reflexões sobre a formação docente. Revista@ mbienteeducação, v. 11, n. 1, p. 163-179, 2018

DE WAAL, F. A era da empatia: lições da natureza para uma sociedade mais gentil. São Paulo: Companhia das Letras, 2010

EBERLE, S. The role of children's mathematical aesthetics: the case of tessellations, Journal of Mathematical Behavior 35, 129-143, 2014.

EUSSE, K. L. G., BRACHT, V. \& ALMEIDA, F. Q.. A prática pedagógica como obra de arte: aproximações à estética do professor-artista. Revista Brasileira de Ciência do Esporte. n. 38. p.1117. 2016.

FARIA, P. C., MORO, M. L. F. \& BRITO, M. R. F.. Atitudes de professores e futuros professores em relação à matemática. Estudos de Psicologia. n. 13. p.257-265. 2008.

FARIA, P. C. Atitudes em relação à matemática de professores e futuros professores. $332 \mathrm{f}$. Tese (Doutorado em Educação) UFPR, 2006

GALLESE, V. The roots of empathy: the shared manifold hypothesis and the neural basis.

Psychopathology, v.36, p.171-180, 2003 
GONTIJO, C. H. Relações entre criatividade, criatividade em Matemática e Motivação em Matemática de alunos do Ensino Médio. 194f. Tese (Doutorado) - UNB, 2007

GONTIJO, C. H. Estratégias de ensino em Matemática e em Ciências que promovem a criatividade: algumas possibilidades. Ciência \& Ensino (ISSN 1980-8631), v. 1, n. 2, 2008.

IMPA. Brasil é promovido à elite da matemática mundial. 25 de Janeiro de 2018. Disponível em https://impa.br/page-noticias/brasil-e-promovido-a-elite-da-matematica-mundial/ Acesso em $28 / 02 / 2018$

LE LIONNAIS, F. Great Currents of Mathematical Thought: Mathematics: Concepts and Development. Courier Corporation, 2004.

LIVIO, M. Razão Áurea: a história de Fi, um número surpreendente. São Paulo: Record, 2008.

MACHADO, N. J. Matemática e realidade: análise dos pressupostos filosóficos que fundamentam o ensino da matemática. São Paulo: Cortez, 1989

MELLO, B. L. C. de. Do olhar ao coração: uma proposta de educação em artes visuais voltada para a empatia. Trabalho de conclusão de curso (Licenciatura em Artes Plásticas)—Universidade de Brasília, Brasília, 2016.

OLIVEIRA, P. A. J.. A aula como espaço epistemológico forte. Universidade de Lisboa. Departamento de Educação da Faculdade de Ciências. 2002.

ORTIZ, R. Cultura e desenvolvimento. Políticas culturais em revista, v. 1, n. 1, 2008.

PELAES, M. L. W. A educação estética e o ensino da arte na perspectiva dos parâmetros curriculares nacionais de arte para o ensino fundamental. 2015 Disponível em: http://artenaescola.org.br/sala-de-leitura/artigos/artigo.php?id=75435 acesso em 23/02/2018

PEREIRA, M. V.. Contribuições para entender a experiência estética. Revista Lusófona de Educação, n. 18, p.111-123. 2011.

PIMM, D.; SINCLAIR, N. Explaining Beauty in Mathematics: An Aesthetic Theory of Mathematics by Ulianov Montano. The Mathematical Intelligencer, v. 39, n. 1, p. 79-81, 2017.

PLATÃO. Timeu-Crítias. Tradução do grego, introdução notas e índices: Rodolfo Lopes. Editor: Centro de Estudos Clássicos e Humanísticos. 1ª edição. 2011.

POINCARÉ, H. Ensaios fundamentais. Rio de Janeiro: Contraponto: PUC Rio, 2008

POLYA, G. A arte de resolver problemas. Rio de Janeiro: Interciência, 1977.

POPPER, K. A lógica da pesquisa científica. São Paulo: Cultrix, 2004.

RUSSELL, B. Mysticism and logic, and other essais. Totowwa, J.J. Barnes \& Noble Books, $1919 / 1951$

SAMPAIO, L.R.; CAMINO, C.P.S.; ROAZZI, A. Revisão de aspectos conceituais, teóricos e metodológicos da empatia. Psicol. Cienc. Prof., v.29, n.2, 2009

SANCHES, A. M. Contemplando a matemática: a geometria espacial da pintura renascentista e suas interações com o ensino acadêmico. Dissertação de Mestrado. Universidade Lusófona de 
Humanidades e Tecnologias Instituto de Educação, Lisboa 2015

STEIN, S. M. S.; FONSECA, M. S. Educação Matemática: A criatividade como elemento motivador no ensino da Geometria. In: $5^{\circ}$ Congreso Uruguayo de Educación Matemática, Montevideo. 2015. p. 445-450.

VIGOTSKI, L. S. A formação social da mente: o desenvolvimento dos processos psicológicos superiores. Tradução: José Cipolla Neto, Luís Silveira Menna Barreto, Solange Castro Afeche. São Paulo. Martins Fontes. 4ª Edição. 1991.

VIGOTSKI, L. S. Imaginação e criação na infância: Ensaio Psicológico - Livro para professores. Apresentação e comentários: Ana Luiza Smolka; tradução Zoia Prestes . São Paulo: Ática. 2009.

VIGOTSKI, L. S. Psicologia da arte. Tradução: Paulo Bezerra. Editora: Martins Fontes. São Paulo. 1998.

ZAGO, H.; FLORES, C. R. Uma proposta para relacionar arte e educação matemática. Relime, México, v. 13, n. 3, p. 337-354, nov. 2010

ZALESKI FILHO, D. (2009) Arte e matemática em Mondrian. Dissertação (Mestrado) Mackenzie, São Paulo.

ZENI, S. ROMAYA, J. P., BENINCASA, D. M. T. \& ATIYAH, M. F. The experience of mathematical beauty and its neural correlates. Frontiers in Human Neuroscience. Vol. 8. Artigo 68.

Fevereiro/2014. 